\title{
Dasein y desengaño en El Zarco, Los de abajo y Pedro Páramo
}

\author{
Dasein and disillusion \\ in El Zarco, Los de abajo y Pedro Páramo
}

Pablo García loaeza

West Virginia University

pablo.garcia@mail.wvu.edu

RESUMEN: Sin perder de vista el marco socio-histórico, este artículo considera los desengaños que sufren los personajes principales de El Zarco de Manuel Altamirano, Los de abajo de Mariano Azuela y Pedro Páramo de Juan Rulfo. Su ardua toma de conciencia encauza la narración, y la manera en que enfrentan sus verdaderas condiciones revela la disposición anímica que los mueve y que bien podría ser eco del desengaño que sentían sus autores ante las realidades que inspiraron sus relatos. Se aprovecha la ontología que propone Martin Heidegger en Ser y tiempo para reflexionar sobre la caracterización de los protagonistas de las tres novelas. Además de revelar el filón existencial de estas obras, esta aproximación invita a considerar la postura filosófica de sus autores.

\author{
Palabras Clave: \\ El ZarCo; \\ Los de abajo; \\ Pedro Páramo; \\ desengaño; \\ filosofía; \\ Martin Heidegger.
}

KEYWORDS:

El Zarco;

Los de abajo;

Pedro Páramo;

Disillusion;

Philosophy;

Martin Heidegger.
ABSTRACT: Without losing sight of the socio-historic backdrop, this article examines the disillusion suffered by the main characters in El Zarco by Manuel Altamirano, Los de abajo by Mariano Azuela, and Pedro Páramo by Juan Rulfo. Their arduous awakening to reality drives the narrative, and the way by which they face their true situations reveals the spiritual bearing that enlivens them and which could very well be an echo of the disillusion the authors felt in view of the realities that inspired their works. The ontology proposed by Martin Heidegger in Being and Time serves to consider the characterization of the three novels' protagonists. Besides revealing these works' existential vein, this approach invites a consideration of their authors' philosophical stance. 
recepción: 17 octubre 2018

aceptación: 13 mayo 2019

Las novelas El Zarco (1901) de Ignacio Manuel Altamirano (1834-1893), Los de abajo (1915) de Mariano Azuela (1873-1952) y Pedro Páramo (1955) de Juan Rulfo (1917-1986) se suelen interpretar, con toda razón, en relación con la situación social de sus respectivas épocas. Como se sabe, El Zarco deplora los dilemas judiciales que suscitó la Guerra de Reforma; Los de abajo denuncia los extravíos de la Revolución mexicana, y Pedro Páramo delata la esterilidad de la misma. Consecuentemente, los personajes aparecen como símbolos del devenir histórico de la nación mexicana y sus desventuras como síntoma de un desorden moral sistémico que algunos encarnan y del que casi todos terminan siendo víctimas. En ese sentido no es difícil reconocer la afinidad entre Pedro Páramo y Los de abajo, tanto formal como temáticamente. ${ }^{1}$ En cambio, queda por registrar adecuadamente el eje anímico-filosófico — por Ilamarlo de alguna manera- que permite conectarlas con El Zarco. Agrupar las tres novelas desde este ángulo revela su filón existencial y permite ligarlo a las actitudes de sus autores vinculadas con circunstancias que, más allá de sus particularidades, ponen en evidencia un constante estado de crisis — un estado en constante crisis- y el malestar anímico que esto provoca. Un aspecto que conecta los textos entre sí, así como con la realidad, es el desengaño, que va aunado a un serio cuestionamiento existencial. ${ }^{2}$

1 Yvette Jiménez de Báez ha identificado consonancias estructurales y temáticas que ligan a Los de abajo con las obras de Rulfo. Françoise Perus también ha estudiado el tema. Por otro lado, Juan Bruce-Novoa señala rasgos recurrentes de las novelas de la Revolución mexicana, incluyendo a Pedro Páramo. Bruce-Novoa destaca la visión negativa que desacredita el levantamiento armado y la degradación de los protagonistas, que terminan descartados o muertos sin que se logre una mejoría notable (1991: 39). Estas apreciaciones, como muchas otras, no ahondan en la dimensión existencial de las novelas.

2 El desengaño es un tipo de anagnórisis, cuya importancia en la estructura de una ficción se conoce desde la Poética de Aristóteles. El presente trabajo enfoca el desengaño no tanto como un recurso literario, sino como eje de una interpretación filosófica de las novelas que aquí se estudian. 
En El Zarco, Los de abajo y Pedro Páramo, el desengaño es un factor clave. Las tres novelas cuentan historias repletas de esperanzas vanas, intenciones extraviadas, planes equivocados y proyectos fallidos. La trama de El Zarco está organizada en torno a las ilusiones de Manuela, quien imagina una vida novelesca al lado de un bandido, pero pronto averigua que su visión romántica no tiene nada que ver con la realidad. En Los de abajo, la jornada de Demetrio Macías va mostrando paso a paso los atropellos, los excesos, los engaños y, en fin, la insensatez de la lucha revolucionaria. En Pedro Páramo, Juan Preciado descubre que Comala es una suma de desilusiones: el destino del pueblo está marcado por los arrepentimientos y las nostalgias de sus habitantes. Al confrontar situaciones muy distintas de las que habían prefigurado, Manuela, Demetrio Macías y Juan Preciado se ven obligados a reconsiderar sus acciones y actitudes pasadas, su condición presente y sus posibilidades futuras. El contraste entre su proyección original y su circunstancia irremediable resulta en una crisis del ser que, cuando no es inmediatamente letal, apunta siempre hacia la muerte, que es el colmo del desengaño. El corazón de Manuela revienta ante la verdad de su desgracia. Demetrio Macías, ya consciente de que la lucha no tiene sentido, cae víctima de una bala cualquiera. Juan Preciado se muere de miedo ante la fantasmagoría comalense - aunque persiste, integrándose a ella. En última instancia, el desengaño y la muerte ponen en evidencia el sinsentido de la condición humana. La toma de conciencia de estos personajes, lo que encauza los distintos relatos, también apunta hacia la disposición existencial que anima y aúna las tres novelas. En otras palabras, detrás de la crítica social que indudablemente expresan, se puede vislumbrar una meditación sobre el ser individual provocada por el desengaño que sentían Altamirano, Azuela y Rulfo ante los trastornos sociales y personales que traslucen sus relatos. ${ }^{3}$

3 No es necesario insistir en la afinidad entre la creación literaria y el pensamiento existencialista. Como señala Stephanie Merrim, la literatura se presta particularmente bien a las preocupaciones de la filosofía existencial por su capacidad de representar vidas individuales en contexto, considerar su totalidad a través de acciones, pensamientos y emociones y contemplar elecciones que encarnan el ejercicio de la libertad (2011: 94). En la primera mitad del siglo xx, el existencialismo se manifiesta en numerosas obras literarias como las de Samuel Beckett, Albert Camus, Jean-Paul Sartre y Miguel de Unamuno, entre muchas otras. 
Como tópico literario, el desengaño se asocia de modo particular con la poesía barroca, en la que se destaca una preocupación intensa por el paso del tiempo y la muerte (Rosales 1966: 42, 43). Dentro del pensamiento filosófico moderno, la temporalidad y la finitud son elementos fundamentales de la ontología que propone Martin Heidegger (1889-1977) en Ser y tiempo (1927), misma que se puede caracterizar como una filosofía del desengaño. Algunas de las ideas de Heidegger sobre lo que él Ilama el Dasein, o el estar-en-el-mundo, ${ }^{4}$ son útiles para especular sobre los desengaños que sufren algunos de los personajes principales de El ZarCo, Los de abajo y Pedro Páramo y sus secuelas desde una perspectiva ontológica.

\section{La analítica del Dasein}

No es posible resumir plenamente la analítica del Dasein en unas cuantas líneas, pero se pueden destacar ciertas ideas que sirven para apreciar cómo funciona el desengaño - la revelación y la aprehensión del estar-enel-mundo- en las novelas en cuestión. Heidegger propone que el Dasein se debe entender, ante todo, en relación al tiempo, y más específicamente a su "temporeidad" (1997: 41). Esta temporeidad no debe confundirse con el tiempo que marca el reloj y va del pasado al futuro pasando por el presente. Para Heidegger, el futuro es lo primordial. Esto se debe a que el Dasein es, originariamente, posibilidad. Entre sus posibilidades está ganarse o perderse a sí mismo, apropiarse de su estar-en-el-mundo o entregarse a una existencia literalmente "impropia". La impropiedad no implica ser menos. ${ }^{5}$ Es simplemente otra manera de estar en el mundo que puede incluso "determinar al Dasein en lo que tiene de más concreto, en sus actividades, motivaciones, intereses y goces" (1997: 68). De hecho, la im-

4 In-der-Welt-sein se suele traducir como "ser-en-el-mundo". Jorge Eduardo Rivera, cuya traducción de Ser y tiempo utilizo aquí, prefiere el verbo "estar" para enfatizar el aspecto existencial de la estructura del Dasein, en lugar del aspecto esencial al que apunta el verbo "ser" (Heidegger 1997: 464). Ambas opciones generan cierta ambigüedad.

5 Heidegger evita intencionalmente el juicio moral. No obstante, resulta difícil no interpretar la "impropiedad" como una falla de carácter. Por otro lado, la literatura no pretende la imparcialidad de la filosofía, sino al contrario. Los personajes de una narración están siempre en tela de juicio. 
propiedad es lo común, pues es lo que caracteriza a das Man, una entidad difusa e inasible que se expresa empleando los pronombres impersonales "uno" y "se" y que, entre otras cosas, prescribe el modo de ser cotidiano: lo que todos hacen en general y nadie en particular. Das Man abstrae al Dasein de sí mismo a través de distracciones que estorban las relaciones genuinas con el mundo y contribuyen a su caída en una alienación tranquilizante. Las distracciones que destaca Heidegger son la curiosidad, una avidez de novedades que impide la plena aprehensión de las cosas; la habladuría, un mero decir repetitivo y superficial que aparta de la realidad; y la ambigüedad, que ofusca la distinción entre lo importante y lo trivial. En conjunto constituyen un modo fundamental del ser de la cotidianidad. Sin embargo, el Dasein tiene también la posibilidad de abrirse a su propio ser apartando encubrimientos y quebrantando disimulaciones (Heidegger 1997:151-153, 192-193, 197-198, 200).

Otra característica constitutiva del Dasein es el estar "arrojado" en el mundo: el estar ahí donde se está, pese a sus posibilidades, es un hecho ineludible. De ese modo el Dasein se define como "posibilidad arrojada". El discernimiento de esa condición provoca una repugnancia que generalmente lo hace huir de sí propio hacia el sosiego que ofrece das Man. Heidegger contrasta este miedo con la angustia, una disposición afectiva que no tiene un objeto específico y por eso abarca todo. ${ }^{6}$ Entregado a esa totalidad vacía, el Dasein puede religarse con su propio poder-serestando-ya-en-el-mundo. En lugar de un desahogo en lo común, este entendimiento provoca una desazón reveladora. La revelación primordial de la angustia es la constante inminencia de la muerte, la posibilidad más propia e insuperable. Cotidianamente, el Dasein encubre su propia muerte, proyectándola como algo que les sucede comúnmente a otros, pero a uno enfáticamente aún no (1997: 160, 207-208, 210-212, 247, 271, 274). Heidegger caracteriza esta actitud esquiva como "un impropio estar vuelto hacia la muerte" (279; énfasis original).

\footnotetext{
6 "El miedo", dice Heidegger, "es angustia caída en el 'mundo', angustia impropia y oculta en cuanto tal para sí misma" (1997: 212). En cambio, "la serena angustia" del Dasein abierto y singularizado se acompaña de una "vigorosa alegría" (329). Esta afirmación no resulta paradójica en el marco de la propuesta heideggeriana.
} 
El modo propio requiere proyectarse hasta la posibilidad inminente de no ser para percibir las ilusiones de das Man como tales y adquirir la libertad para la muerte. Esto implica elegir resueltamente ser sí mismo — que es lo opuesto de ser uno mismo, que es uno cualquiera y ninguno (285, 289). De ninguna manera se trata de ansiar morir, sino al contrario, de asumir resueltamente el hecho de estar en el mundo y, desde siempre, a un paso de la muerte. La resolución, tal como la propone Heidegger, no está dirigida hacia un objeto u objetivo particular, se trata de una manera de proyectarse, de una "determinación existencial" (316; énfasis original). No obstante, "una vez que la resolución, adelantándose, ha introducido en su poder-ser la posibilidad de la muerte, la existencia propia del Dasein no puede ser ya superada por nada más" (326; énfasis original). En otras palabras, el Dasein es plenamente sí mismo cuando asume resueltamente el hecho de ser un ser-hacia-su-muerte, lo cual le permite disipar "todo autoencubrimiento rehuyente" y actuar sin hacerse ilusiones (328).

La proyección apunta hacia el futuro, que es el aspecto primordial de la "temporeidad" originaria del Dasein propio. El Dasein es un "ser venidero" que sólo volviendo hacia sí mismo desde su poder-ser futuro puede haber sido o, mejor dicho, concebir su pasado. El volver venideramente genera el presente, que brota del futuro que está siendo sido. ${ }^{7}$ El origen de la angustia liberadora es el futuro, mientras que el miedo surge en realidad del presente perdido $(343-344,346,361)$. En suma, el Dasein propio es un ser desengañado que, asumiendo plenamente su condición arrojada, se proyecta resueltamente hacia su propio fin y acepta que la existencia no tiene más sentido que el existir. En contrapartida, el Dasein impropio tiende a ofuscarse, a huir hacia la inercia de lo común. El descubrimiento de la verdad asegura al primero, mientras que espanta al segundo. En el mundo que recrean El Zarco, Los de abajo y Pedro Páramo, la manera en que los personajes protagónicos reaccionan ante el desengaño se puede interpretar a partir de las dos modalidades del Dasein para entender no sólo el tenor existencial de cada una de las novelas, sino el humor que lo inspira. Los reveses que sufren y sus repercusiones se pueden interpretar

7 Heidegger aclara que no se debe pensar en la temporeidad ontológica como una sucesión: "el futuro no es posterior al haber-sido, ni éste anterior al presente. La temporeidad se temporiza como futuro que está-siendo-sido y presentante" (1997: 366). 
como experimentos existenciales que manifiestan la actitud de Altamirano, Azuela y Rulfo ante las vicisitudes históricas de las que fueron testigos.

\section{Verdades aterradoras}

En El ZarCo, las apariencias engañan y fiarse de ellas puede ser fatal (cfr. Monsiváis 1999: 13). Se descubre, por ejemplo, que detrás de la galanura del Zarco se oculta un alma rastrera y si Nicolás no brilla por su aspecto físico, deslumbra por su carácter moral. Pero los engaños y los desengaños más agudos son los de Manuela pues provocan crecientes crisis existenciales que pautan la narración, subrayan la lección moral de la novela y suman una reflexión ontológica. En una novela en la que el bien y el mal están netamente definidos, Manuela es el personaje más complejo y su proceso sicológico y emocional recibe particular atención. Pronto se descubre que la hermosa Manuela, quien no es como parece, inconforme con su vida provinciana, se debate en una disyuntiva interna. Al pie de la adelfa donde oculta las joyas mal habidas que le regala el Zarco se libra "un tremendo combate entre los últimos remordimientos de una conciencia ya pervertida, y los impulsos irresistibles de una codicia desenfrenada y avasalladora" (Altamirano 1986a: 129). La codicia termina venciendo y Manuela queda engañada sobre su propio ser. Mirándose en un estanque para ver cómo le quedan las joyas, se da aires de gran señora, pero el narrador aclara que se trata, en realidad, de "la perversidad contemplándose en el cieno" (129). El resto de la novela es, en gran medida, el paulatino descubrimiento de la realidad por parte de Manuela, a través de una serie de revelaciones que la confrontan con la verdad de su ser. ${ }^{8}$

El primer desengaño de Manuela ocurre en Xochimancas, la guarida de los plateados, donde, luego de fugarse con el Zarco, descubre que la vida entre bandidos no es como ella creía. Manuela imaginaba "una existencia de aventuras peligrosas, es verdad, pero divertidas, romancescas, originales", pero los hábitos repugnantes de los malhechores pronto

${ }_{8}$ El descubrimiento de la verdad, que Heidegger identifica con el concepto griego de alétheia, es constitutivo del Dasein (1997: 240-241). No es una cuestión de distinguir lo cierto de lo falso, sino de develar lo que atañe a la existencia y fundamenta las decisiones y el carácter de las relaciones con otros (King 2001: 107). 
la decepcionan: “jesús!... ¡lo que he ido a hacer!”. El contraste entre la fantasía y la realidad provocan un examen de conciencia que la lleva a "comprender con terror" que se había dejado arrastrar por "una codicia desenfrenada, loca, verdaderamente absurda". Abrumada por esta idea, procura negarla atribuyéndole su desenfreno a la pasión que sentía por el Zarco. Pero éste tampoco es como ella pensaba. Así, "Manuela creía salir de un sueño horrible. Habíanle bastado algunas horas para comprender todo lo execrable de su pasión, y todo lo irremediable de su desventura. Y era que, desvaneciéndose su ilusión malsana, y apagándose por eso la Ilama impura que había abrasado su corazón, iba reapareciendo la luz en su conciencia y palpándose la fría realidad con su cortejo de verdades aterradoras". A raíz de esta crisis existencial, cae en una clara y profunda depresión. Intenta mantener una apariencia de contento, pero la nostalgia de lo que hubiera podido ser le impide disimular su desazón. La siguiente toma de conciencia de Manuela es letal. Los bandidos han caído en manos de la ley y el Zarco ha sido ejecutado en presencia de Manuela, quien en ese momento parece, otra vez, despertar de un sueño. Grita que en realidad quiere ser la querida de un ladrón, contempla su entorno, se lleva las manos al corazón, da un grito agudo y cae al suelo, muerta (Altamirano 1986a: 181-82, 193, 198-199, 206, 240). El relato termina junto con ella.

Las actitudes de Manuela, en relación con sus ilusiones y sus desengaños, ejemplifican el contraste que Heidegger propone entre el Dasein propio, que asume resueltamente su condición, y el Dasein impropio, que ofusca la realidad. A Manuela se le presentan ambas opciones, lo que la distingue del resto de los personajes, más planos, de la novela, y sugiere posibilidades de interpretación que van más allá de la voluntad didácticomoralizante que se le suele atribuir a Altamirano. Manuela se caracteriza primeramente por pretensiones enceguecedoras. Se niega, por ejemplo, a considerar las virtudes de Nicolás, a quien considera "un indio horrible", o el hecho de ser, como le señala su madre, "una pobre muchacha". En cambio, se extravía en una "pasión frenética" y se abandona a la ambición y la codicia (1986a: 107, 108, 125). Ésta, como una proyección hacia algo que no se tiene, se podría agregar a la lista de distracciones alienadoras del propio estar-en-el-mundo. 
En sus momentos de desengaño Manuela logra ver las cosas con claridad, pero entonces la tribulación y el miedo la vuelven a la impropiedad. Ya desilusionada de la idea romántica que tenía del bandidaje, Manuela examina profundamente su conciencia y entiende que su motivación no era en realidad la pasión, sino una codicia excesiva e insensata. Sin embargo, tal consideración la irrita y la niega "con una gran apariencia de razón". A pesar de ello, no puede evitar pensar en las posibilidades que abandonó y "así, abrumada por tantas emociones, torturada por tantos remordimientos, se apoderaba de ella el desaliento, el tedio de la vida y sentía que su razón iba a perderse". Un poco más adelante, Manuela se da cuenta que todo "lo que le pasaba e iba a pasarle todavía no era más que la consecuencia ineludible de su aturdimiento, de su ceguedad, de su insensatez", y parece estar resuelta a asumir su suerte: "precipitada de cabeza en el abismo, no había desviación posible; tenía que caer hasta el fondo". Pero "a esta consideración, Manuela sentía circular en su cuerpo un calofrío de muerte, y se apoderaba de ella un fuerte deseo de escapar" seguido de "un desmayo y un desaliento indecibles". Se decide entonces a fingir, a disimular hasta que surja la oportunidad de huir y reintegrarse a la normalidad de una vida humilde entre gente honrada (1986a: 198, 199, 203). Todo este proceso ilustra los efectos del miedo que, según Heidegger, priva al Dasein de sí mismo, lo confunde y lo hace perder la cabeza, huir de su propio poder ser y caer en el abatimiento (1997: 165, 212).

No obstante, al final del relato, Manuela asume plenamente su condición. No es cuando dice que prefiere morir que ver a Pilar y a Nicolás felizmente casados, que es todavía una proyección huyente, un rechazo de la realidad; es cuando se identifica consigo misma alineando contundentemente su voluntad con su situación: "yo soy la que tengo la corona de rosas...; yo no quiero casarme, yo quiero ser la querida del Zarco, un ladrón!" (Altamirano 1986a: 240). El patetismo de la situación no da pie a la ironía. En cualquier caso, esta postura anula las posibilidades del personaje puesto que va en contra de las nociones que defiende la novela. En ese contexto, la determinación de Manuela no puede tener futuro. Darle la oportunidad de existir propiamente, sin ilusión y sin miedo, habría sido demasiado radical. Manuela debe morir inmediatamente. Pero justo antes se vislumbra una resolución ontológica, la aceptación del estar-en- 
el-mundo arrojado, sin ilusiones. Esa comprensión se ve más claramente en Los de abajo.

\section{- Mira esa piedra cómo ya no se para...}

Los de abajo es, en gran medida, la historia del peregrinaje de Demetrio Macías de la ilusión a la verdad. Comparte o se encuentra en el camino con varios ilusos que tratan de engañarse a sí mismos, algunos charlatanes que pretenden engañar a otros y un par de escépticos. Por ejemplo, la manera de hablar de Anastasio Montañés, cuestionando siempre la confianza de sus oyentes, sugiere su poca fiabilidad, mientras que el contraste entre las palabras y el comportamiento de Luis Cervantes delatan su hipocresía (Sklodowska 1994: 27, 32). Por otro lado, Alberto Solís y el loco Valderrama denuncian con gran lucidez las incoherencias de la lucha armada. Pero Demetrio Macías es el único personaje que cambia a lo largo del relato, yendo de la inocencia, al aturdimiento, a la conciencia. Poco a poco se va desengañando hasta asumir una postura ante su situación en medio del conflicto revolucionario que corresponde al estar-en-el-mundo propio, resuelto. Al principio no está del todo claro por qué lucha, aunque hay alusiones a los abusos de las fuerzas del gobierno y un conflicto personal con un pequeño jefe político. No defiende ninguna causa y lo único que desea es que lo dejen en paz para volver a su casa (Azuela 1958: 322$323,332,347)$. Luis Cervantes, palabrero y ambicioso, lo embelesa con nociones grandilocuentes:

Usted no comprende todavía su verdadera, su alta y nobilísima misión. Usted, hombre modesto y sin ambiciones, no quiere ver el importantísimo papel que le toca en esta revolución. Mentira que usted ande por aquí por don Mónico, el cacique, usted se ha levantado contra el caciquismo que asola toda la nación. Somos elementos de un gran movimiento social que tiene que concluir por el engrandecimiento de nuestra patria. Somos instrumentos del destino para la reivindicación de los sagrados derechos del pueblo (1958: 348).

Demetrio se entrega plenamente a la ilusión y llega a desaparecer en ella. Cuando Alberto Solís lo felicita por sus aventuras, queda encantado con "el relato de sus hazañas, compuestas y aderezadas de tal suerte, 
que él mismo no las conociera. Por lo demás, aquello tan bien sonaba a sus oídos, que acabó por contarlas más tarde en el mismo tono y aun por creer que así habíanse realizado" (1958: 362). Pero pronto la realidad se empieza a imponer sobre la quimera.

Al inicio de la segunda parte de la novela hay un momento significativo en el que Demetrio Macías "saca su repetición de oro incrustado de piedras y pide la hora a Anastasio Montañés". El compadre mira la carátula, saca la cabeza por una ventana $y$, juzgando por las estrellas, anuncia que no dilata en amanecer. No es sólo que la luz del día pronto ha de poner en evidencia los excesos de los revolucionarios, sino que el ostentoso reloj de Demetrio no da cuenta cabal de la hora que se aproxima. Algo parecido sucede cuando recibe su insignia de general: "¿Y qué voy a hacer ahora yo con este zopilote?". El "avance" es engañoso y el acenso carece de sentido; la pretensión ambiciosa no lleva a nada. Después de ejercer su venganza personal sobre su viejo enemigo, el cacique de Moyahua, Demetrio Macías cae en el abatimiento. El dinero y las joyas que le ofrece Luis Cervantes no le interesan. En cambio, imagina que Camila, la joven humilde que conoció en la primera parte de la novela, puede aliviar su tedio, aunque, ya que están juntos, ella no hace sino acompañarlo en el sentimiento. "¡Yo no sé qué siento por acá que me da tanta tristeza!", dice Demetrio y Camila responde: "Lo mismo a mí". Demetrio despierta a una vaga angustia: "A mí me va a suceder algo', pensó", pero luego de la muerte repentina de su amante, se abandona a su desazón (1958: 373, 377, 392-393, 398).

En la tercera parte, Demetrio Macías se muestra ensimismado, meditabundo. Cuando, luego de recibir la noticia de la derrota de Pancho Villa en Celaya, el loco Valderrama pone la Revolución en perspectiva al decir que los caudillos revolucionarios son equivalentes entre sí y que él ama la Revolución en sí, sin importarle sus consecuencias políticas, Demetrio comenta cómo le tiene voluntad "porque a veces dice unas cosas que lo ponen a uno a pensar". Demetrio también enfoca la lucha con más claridad que en la sección anterior. Cae en cuenta de cómo, a pesar del desorden, el disgusto y las quejas, él y sus hombres siguen "a reniega y reniega y a mátenos y mátenos" neciamente. Pero también entiende que eso no hay que decirlo, que lo que se debe hacer en cambio es animar a la 
gente. Cada vez se pone más en evidencia la muy examinada circularidad del relato, pero también lo absurdo de la lucha revolucionaria. Vuelto a su punto de partida, la esposa de Demetrio, luego de pedirle inútilmente que se quede, le pregunta por qué siguen peleando. Demetrio, pensativo, arroja una piedra al fondo de un barranco y dice: "Mira esa piedra cómo ya no se para..." (1958: 410, 413, 416). Al final, atrapado en una emboscada, Demetrio se encuentra solo. No intenta escapar. Cobra cara su vida, mirando de frente su destino fatal mientras la naturaleza se mantiene imperturbable y del todo indiferente.

Christopher Harris arguye que, para el final de la novela, frustrado irremediablemente y aquejado por una melancolía patológica, Demetrio Macías opta por suicidarse $(87,30)$. La congoja es evidente, pero no es enfermiza, sino el resultado de una serie de fuertes adversidades de la fortuna que no son para menos. Pero, desde el principio del relato, Demetrio ha demostrado que no se apoca ante los retos, sino al contrario. Al final, no decide entregarse a la muerte - que lo encuentra casi como por casualidad - sino al existir y de manera resuelta. La piedra que tira al barranco no es solamente una metáfora de la lucha armada, impulsada ante todo por su propia inercia. También se puede interpretar como una representación del propio estar-en-el-mundo, arrojado y sin más sentido que la existencia misma. Más allá de la palabrería, de la ambición y del sentimiento, no hay más que seguir rodando. Demetrio no deja de luchar hasta el final, a pesar de haber entendido que no hay nada por qué luchar. Sabiendo, sin duda, que va a morir, sigue disparando hasta el final, contento de su buena puntería.

Los de abajo es una novela llena de reveses y desengaños. Entre otros muchos, se pueden destacar la decepción que padece Luis Cervantes, quien reniega tanto de los federales como de los revolucionarios; la desilusión que siente Alberto Solís ante las amargas realidades de la Revolución; y el despecho de Camila por el desdén y luego la traición de Luis Cervantes. También hay numerosos ejemplos de crueldad y codicia. Aunque el güero Margarito y La Pintada descuellan, respectivamente, en lo uno y en lo otro, el narrador apunta que los temas de "yo maté" y "yo robé" parecen igualmente inagotables (Azuela 1958: 72, 112). Ese "yo" es en realidad todos y cualquiera. Los pocos que cuestionan el caos revolucionario, se 
dan al cinismo como Luis Cervantes, a la lamentación como Alberto Solís o a la ebriedad como Valderrama. Éste, por lo menos, tiene la virtud de ser poeta, mientras que aquéllos son sólo un par de cuenteros; ninguno es valiente. De un modo u otro todos estos personajes procuran evadir la realidad — con habladurías como los curros, con alcohol como Valderrama, con fachas como La Pintada o incluso suicidándose como el güero Margarito. Demetrio es distinto. Mata, pero sin saña; lucra, pero sin avidez; se enamora, se entristece y, para olvidar, se emborracha, pero no se pierde; sus palabras no dan lugar a equívocos; y cuando hay que entrar en acción, lo hace decididamente. Las contrariedades que sufre lo cimbran, pero no lo derriban. Al contrario, a fuerza de desengaños termina aceptando su condición propia de arrojada-posibilidad-hacia-la-muerte. ${ }^{9}$ No por nada muere con los ojos abiertos. En cambio, lo que impera en Pedro Páramo es la ilusión.

\section{—¿La ilusión? Eso cuesta caro}

Pedro Páramo ha sido atinadamente caracterizada como "un tratado del desengaño" (Ortega 2003: 340). Al principio de la novela, Juan Preciado explica cómo es que quiso ir a Comala: "Comencé a llenarme de sueños, a darle vuelo a las ilusiones". Su imaginación había sido avivada por la nostalgia de su madre, quien recordaba una hermosa llanura verde y llena de vida, pero lo único que el hijo encuentra al llegar es tristeza, abandono y falsas expectativas. "Todo parecía estar como en espera de algo", comenta Juan Preciado. En realidad, no hay nada que esperar porque ahí ya no vive nadie (Rulfo 2005: 6-9). Sólo quedan los fantasmas, espíritus encadenados a sus deseos, sus frustraciones y sus culpas. Pedro Páramo se aferra al recuerdo de Susana San Juan como ella al de Florencio; Dorotea la Curraca se afana en buscar al hijo que siempre quiso tener; el padre Rentería se

9 A partir de una perspectiva muy distinta, Diarmuid Bradley alcanza conclusiones equivalentes. Bradley plantea que, aunque desilusionado, Demetrio Macías, "is determined, nonetheless, to fulfil his duty and thereby impose himself on adverse circumstances" [está decidido, no obstante, a cumplir su deber y así imponerse sobre circunstancias adversas] y "resolutely rides towards his destiny" [cabalga resueltamente hacia su destino] (21-22; traducción del autor). 
recrimina por su simonía; y nadie puede desligarse del "rencor vivo" que es Pedro Páramo. Incluso Juan Preciado, quien, a pesar del desengaño, no logra largar anhelos alimentados por nostalgias ajenas.

Comala también está lleno de ecos mudos, de voces y palabras que no suenan, sino que se sienten. Pertenecen a los muertos de Comala que, incapaces de hacer otra cosa, no hacen más que hablar de lo que fue, de lo que hubieran querido que fuera y de lo que no pudo ser. En otras palabras, no cesan de repetirse sus añoranzas, sus anhelos y sus desengaños. El incesante murmurar mata de miedo a Juan Preciado, literalmente. Así se lo explica a Dorotea: "Me mataron los murmullos. Aunque ya traía retrasado el miedo. Se me había venido juntando, hasta que ya no pude soportarlo. Y cuando me encontré con los murmullos se me reventaron las cuerdas". El miedo lo aqueja aun cuando no hay nada que temer. Su compañera de tumba le intima: "Ya déjate de miedos. Nadie te puede dar ya miedo" (2005: 8, 44, 51, 62, 65). Pero el miedo perdura más allá de la muerte porque está ligado a un modo de existir paradójico.

La verdadera tragedia de Juan Preciado, y de todos los comalenses, es el subsistir más allá de la vida. Esa modalidad existencial desafía los límites de la analítica del Dasein porque desarticula la temporeidad, que es un aspecto constitutivo del estar-en-el-mundo. ¿Cómo existen, entonces, los muertos persistentes de Comala? Puesto que el Dasein se define por su capacidad —necesidad, incluso- de proyección, la imposibilidad del futuro, aunada a la continuación de la conciencia, los obliga a proyectarse viciosamente hacia el pasado. Susana San Juan resume el problema cuando, tras volver a soñar con eventos pretéritos, se pregunta: “¿Por qué ese recordar intenso de tantas cosas? ¿Por qué no simplemente la muerte y no esa música tierna del pasado?" (2005: 106)..$^{10}$ La fragmentación estructural del texto resulta en una impresión de atemporalidad, de un presente eterno (Toro 1992: 223, 231). Pero dentro de la experiencia subjetiva de los personajes, la retroproyección es inseparable de la muerte. En su delirio final, Juan Preciado siente "como si hubiera retrocedido en el tiempo". Igualmente, en su agonía, los ojos de Pedro Páramo "saltaban de un re-

10 La pregunta es en relación a los sueños que Susana tiene antes de morir, pero ella sigue soñando después de muerta. 
cuerdo a otro, desdibujando el presente" y siente miedo al pensar en la oscuridad llena de fantasmas con los que ha de quedar encerrado (Rulfo 2005: 58, 132). Este proceso corresponde, dentro la analítica del Dasein, a la temporización del miedo, cuyo origen es en realidad "el presente perdido, que medrosamente tiene miedo del miedo y así cae justamente en él" (Heidegger: 361). La palabra "fantasmas" podría remplazarse por "recuerdos" y, al sumirse temerosamente en ellos Pedro Páramo se aliena, como los demás espíritus comalenses, del propio estar-en-el-mundo.

Peor aún, la "atemporeidad" que implica el ya estar muerto elimina la posibilidad del Dasein propio, cuya característica principal es la capacidad de proyectarse resueltamente hacia la muerte. Carentes de esa facultad, los inquietos difuntos de Comala tampoco pueden asumir su condición arrojada - y así descansar en relativa paz por lo menos. Su imperfecto modo de estar en el mundo los condena a la impropiedad. Así, privados de sí mismos, se amparan en lo ordinario de la curiosidad, la habladuría y la ambigüedad. Se distraen procurando oír lo que otros dicen o revisitando morbosamente fragmentos del pasado cuyo significado no siempre es claro. Así, por ejemplo, Juan Preciado interroga a Dorotea sobre los muertos que los rodean y ella le pide que cuando vuelva a oír a Susana San Juan le avise porque le gustaría saber lo que dice. Y se entiende que Susana no hace más que recordar, sin obtener ninguna respuesta, ninguna resolución. Ése es también el caso de Pedro Páramo, con su costal repleto de recuerdos, o del padre Rentería, que se acusa y se justifica en igual medida por lo que hizo y por lo que no. Como ecos, las memorias se fragmentan $y$, aunque parecen inteligibles, no significan nada para quienes rememoran. La repetición insignificante resulta en una tautología pues, a fin de cuentas, cada recuerdo, como el sueño maldito de Dorotea, sólo "prueba lo que te demuestra" (Rulfo 2005: 83, 71, 77, 65).

En Pedro Páramo no pasa nada en realidad. Una vez que se revela que Juan Preciado ha estado muerto desde el principio, como todos los narradores intradiegéticos, no puede pasar nada, porque ya ha pasado todo. Al final de la novela los personajes están como al comienzo. Sin futuro, existen sólo a medias, revisitando constantemente el pasado sin poder modificarlo. La conciencia que tienen de estar muertos resulta en una paradoja no sólo de la existencia, sino del desengaño. Han sobrepasado 
"la posibilidad más propia, irrespectiva e insuperable" del Dasein, pero siguen esquivándose. Después de haber pagado el alto precio de la ilusión, tendrían que estar más allá de ella, pero siguen cayendo en la tentación de justificarse en función de otros, en la tranquilización que resulta de ocuparse de lo ajeno y en la consecuente alienación de sí mismos que caracterizan el impropio estar-en-el-mundo (Heidegger: 271, 274). Esto se debe en parte a que, sin poder avanzar, no tienen más remedio que volver atrás, aunque el afán de re-visitar esperanzas frustradas pudiera sugerir también un cierto masoquismo. Obviamente, sin embargo, el aparente regodeo de los personajes de la novela en re-vivir sus historias fallidas resulta de la voluntad del novelista de ponerlos en tales circunstancias. Más allá de la viabilidad de aplicar la analítica del Dasein a personajes ficticios, las actitudes que les asignan sus autores invitan a considerar las de éstos en cuanto a las realidades con las que sus novelas están claramente relacionadas.

\section{Cuadros sombríos de desencanto y pesar}

El Zarco, Los de abajo y Pedro Páramo reflejan un largo periodo de tensión marcado por las deficiencias políticas, económicas y sociales del régimen porfirista, la violencia revolucionaria y las controversiales secuelas de la lucha armada. Altamirano, Azuela y Rulfo experimentaron las vicisitudes de cada una de esas etapas y captaron en sus obras no sólo parte de la realidad de los hechos que narran, sino su despecho ante, respectivamente, la decadencia de la república liberal, el desenfreno de la revolución y la desolación que ésta produjo. La frustración, la resignación y el desconsuelo que marcan el destino fatal de los personajes principales de sus novelas pueden leerse también como ecos de las desilusiones que sufrieron los tres autores y su actitud ante ellos.

Alejandro Rivas Velázquez señala que, para cuando escribe El Zarco, Altamirano estaba completamente desencantado de las ideas estéticas, políticas y sociales que habían inspirado a los liberales mexicanos en la primera mitad del siglo xix. Rivas Velázquez atribuye la elección del tema de la novela a una voluntad de denunciar la realidad del país y criticar la literatura basada exclusivamente en la ficción a través del contraste entre el bandido de folletín con el que sueña Manuela y los bandidos "reales" 
que descubre en Xochimancas. No obstante, observa atinadamente que la novela muestra el desencanto de Altamirano ante el fracaso en la aplicación de sus ideales políticos y sociales y, más aún, que "el desencanto que sufre Manuela en El Zarco es similar al que experimenta Altamirano con respecto a las teorías románticas y al gobierno liberal" (Rivas Velázquez 1992: 184-185).

En los fragmentos de la novela póstuma Atenea (1935), escritos poco después de haber concluido El Zarco, el giro de lo social hacia lo personal también sugiere la desilusión de Altamirano. Una desazón fatal, lleva al protagonista a alejarse de su patria: "la América no es el desierto en que deseo vivir los negros días de marasmo y de tedio que no me atrevo a abreviar todavía, porque lo creo inútil, convencido de que son ya pocos". Dispuesto a morir en Venecia, la visión de una mujer hermosa envuelve su espíritu en una "nube sofocante y oscura; una especie de desengaño punzante y abrumador que me obliga a filosofar sobre los grandes afectos del alma". De hecho, el último fragmento del texto es un largo ensayo, en forma de carta, sobre el amor, sobre cómo depende de los sentidos, sobre cómo distrae de todo, hasta de la muerte, "la implacable y la inesperada", que es lo único que puede regresarnos a la realidad. Por otra parte, resultan reveladores los rasgos que el protagonista admira en Atenea más allá de la belleza física: "Ni el menor rasgo de curiosidad, ni de orgullo, ni siquiera la conciencia de su prestigio. Era una niña grande, predispuesta a las sorpresas, interrogando a la vida, pero mirándola de frente, sin miedo; segura de su bondad y de su fuerza" (Altamirano 1986b: 243, 248, 286$87,270)$. Mientras que las reflexiones del protagonista tienen un evidente tenor existencial, esta caracterización, antitética de la de Manuela, apunta hacia la resolución como un ideal deseable.

En cuanto a Los de abajo, se suele nombrar a Alberto Solís como el portavoz de las opiniones sobre la Revolución del autor (Jiménez de Báez 1992: 850). Más precisamente, en el repaso que hace de su producción literaria, Azuela se identifica con la idea, expresada por Solís en la novela, de que quien se entrega a la Revolución es como "la miserable hoja arrebatada por el vendaval" (1960b: 1081). No obstante, Solís tiende a la hipocresía, como cuando recompone las hazañas de Demetrio Macías (1958: 362). Tal conducta contrasta con la predilección de Azuela por las 
personas que, en los transes peligrosos de la vida, optan por conservar íntegra la propia autenticidad a costa del fracaso frente a quienes la abdican en nombre del éxito. Lo cierto es que, como Solís, Azuela pronto se desilusionó con la Revolución. Así lo admite cuando comenta cómo sus experiencias entre los revolucionarios hicieron que la impresión favorable que tuvo inicialmente se fuera "desvaneciendo en un cuadro sombrío de desencanto y pesar". Por otra parte, los reveses de esa época también le permitieron percatarse de "la enorme importancia del cultivo del carácter como tesoro insustituible en los momentos amargos y críticos de nuestra existencia". Por eso es justo pensar que el personaje que representa un modelo a seguir es Demetrio Macías. Literalmente incluso, pues si "hubiera encontrado entre los revolucionarios un tipo de la talla de Demetrio Macías", dice Azuela, "lo habría seguido hasta la muerte" (1960b: 1047, 1080, 1090, 1082).

La caracterización de Demetrio Macías corresponde a una cierta idea sobre la manera correcta de estar en el mundo expresada por Azuela al afirmar, en 1950, que, a pesar de los años, no había disminuido su "fervor por los hombres de lucha que saben arrojarse en el torbellino de la vida sin miedo de ser arrebatados y aniquilados por él. La secular idea de los místicos de todas las religiones de que el hombre que quiera ganarse ha de perderse, puesta hoy a la moda por ciertos existencialistas que asientan que el hombre que sabe que se frustra en el frustrarse lee la cifra de su ser, es doctrina que de siempre me ha seducido" (1960a: 701). Aunque no especifica quiénes son los existencialistas a los que se refiere, ${ }^{11}$ el talante que admira Azuela concuerda cercanamente con las características que

11 Podría tratarse de Sartre, quien publicó El ser y la nada en 1943, o de Camus, autor de La peste (1947), novela en la que un médico contempla el sinsentido de la existencia sin darse por vencido. Por otro lado, aunque la primera traducción al español de El ser y el tiempo, realizada por José Gaos, no se publicó sino en 1951, Oswaldo Díaz Ruanova señala que el esplendor de Heidegger en México se había iniciado en 1942 a través de las clases que impartían el mismo Gaos y Juan David García Bacca, ambos exiliados españoles. A finales de esa década, varios alumnos de Gaos -Emilio Uranga, Jorge Portilla, Luis Villoro, Ricardo Guerra y Joaquín Sánchez McGregor, entre otros- constituyeron el grupo Hiperión, de marcada tendencia existencialista (Díaz Ruanova: 21, 201-203). Adyacente al Hiperión, Octavio Paz desplegaba en El laberinto de la soledad (1950) ideas de corte heideggeriano tales como la alienación, la autenticidad y la inautenticidad (Merrim 2014: 312-313). 
Heidegger le atribuye al Dasein propio, que también se puede describir como un ser desengañado que contempla (sabe, lee) su condición arrojada (que se frustra) y no deja de proyectarse (arrojarse) resueltamente (sin miedo) hacia la posibilidad última (ser aniquilados). En sus reflexiones, Azuela confirma también la pertinencia de relacionar el mundo narrado con el mundo real al aseverar que uno de los propósitos fundamentales de la mayor parte de sus novelas fue dar un trasunto del medio y del momento que había estado viviendo (1960b: 1098). Así, los desengaños que se haIlan en Los de abajo pueden leerse como reverberaciones del desencanto de Azuela, mientras que Demetrio Macías puede verse como espejo de la disposición apropiada ante las convulsiones de la existencia.

Una serie de muertes violentas en su familia convulsionaron tempranamente la vida de Juan Rulfo. En una entrevista, las relacionó directamente con Pedro Páramo: "Tal vez en lo profundo haya algo que no esté planteado en forma clara en la superficie de la novela. Yo tuve una infancia muy dura, muy difícil. Una familia que se desintegró muy fácilmente en un lugar que fue totalmente destruido [...] Entonces viví en una zona de devastación. No sólo de devastación humana, sino devastación geográfica. Nunca encontré, ni he encontrado hasta la fecha, la lógica de todo eso" (Sommers 2003: 519). Aunque Rulfo no se lo atribuye a la Revolución, la crítica considera — acertadamente, creo-que el contenido de sus obras está inevitablemente ligado a la realidad del México posrevolucionario (Blanco Aguinaga 2003: 43; Muñoz 1985: 396; Rodríguez Monegal 2003: 134). Sea como sea, Rulfo declara que la escritura de la novela estuvo ligada a un cierto estado anímico. "Cuando escribí Pedro Páramo", explicaba, "sólo pensé en salir de una gran ansiedad. Porque para escribir se sufre en serio" (1985: 7). Así, no sorprende que varios comentaristas hayan encontrado en la novela una problemática de orden existencial. Carlos Blanco Aguinaga contrasta la tristeza y desencanto reflexivo de un escéptico-optimista como Azuela con la postura de Rulfo, cuya escritura capta "la angustia del hombre moderno [...] para quien todas las cosas que lo rodean son símbolos mudos" (20). Mariana Frenk opina que el verdadero tema de Pedro Páramo es "el hombre, su vida, su sufrimiento y su morir" (53). En particular, Stephanie Merrim afirma que el existencialismo es una de las vías que convergen en una novela que se 
gestó durante un periodo, entre los años cuarenta y principios de los cincuenta, en el que esa corriente filosófica gozaba de gran auge en México (2014: 308-309)..$^{12}$

Según palabras del propio Rulfo, la exploración del estar en el mundo era parte consustancial de su escritura. En una "autobiografía" armada con entrevistas y textos en primera persona, Rulfo reconoce que a través de la escritura buscaba desahogarse de la soledad en la que había vivido desde la infancia. Era una especie de diálogo que él hacía consigo mismo y, más aún, con la soledad. Esas cavilaciones alcanzan una dimensión filosóficoexistencial cuando Rulfo agrega: "El hombre está solo. Y si quiere comunicarse lo hace por medios que están a su alcance. El escritor no desea comunicarse, sino que quiere explicarse a sí mismo". Pero el escribir no ofrece una liberación, sino al contrario. En el coro de "las voces universales y gloriosas", Rulfo atendía "la voz profunda y oscura [...] Y aunque Ud. no lo cree, esa voz predomina en el coro, y es la del verdadero, la del único solista en que creo, porque me habla desde lo más hondo de mi ser y de mi memoria". Ahí se halla el origen de su escritura, definida como una transposición literaria de los hechos de su conciencia, que "no es una deformación, sino el descubrimiento de formas especiales de sensibilidad" (Roffé: 53, 62-63, 72-73; énfasis original). La soledad de los muertos de Comala y su afán de mirar siempre hacia el pasado buscando inútilmente el sentido de su tránsito por el mundo espejean las reflexiones de Rulfo. La diferencia fundamental es que, mientras que los personajes persisten en la impropiedad, el autor que los coloca en tal situación contempla, resueltamente al parecer, los elementos constitutivos del Dasein: la condición arrojada y la inminencia constante de la muerte.

El Zarco, Los de abajo y Pedro Páramo poseen una dimensión existencial que está indudablemente ligada no sólo a la circunstancia histórica de sus

12 Merrim señala que Rulfo asistió a las clases que impartía Antonio Caso en el edificio Mascarones de la Facultad de Filosofía y Letras de la UNAM; Caso fue uno de los primeros intelectuales en difundir las ideas de Heidegger en México. Merrim apunta también que las lecturas existencialistas de Rulfo incluyeron La náusea (1938) de Sartre y considera que Pedro Páramo dialoga directamente con El laberinto de la soledad (2014: 310-311, 314). 
respectivos autores, sino a la disposición anímica de cada uno de ellos. El punto de articulación entre una cosa y otra es el desengaño. Éste constituye una especie de puente entre la realidad y la ficción pues los desengaños que enfrentan Altamirano, Azuela y Rulfo repercuten en los que afrontan los personajes de sus novelas. Sin embargo, el propósito de establecer tal nexo no es sicoanalizar a los unos a través de los otros. Tampoco se pretende precisar la intención de los autores, incluso en lo que respecta a la aparente crítica de las condiciones sociales que recrean en sus relatos. El objetivo es, por un lado, registrar los matices filosóficos de estas tres novelas escritas en tiempos difíciles que afectaron personalmente a sus autores. La aproximación a partir de la analítica del Dasein propuesta por Heidegger permite entender la dinámica de la narración en relación a la perspectiva que la alimenta. Revela que, más allá del reflejo de una realidad externa, estas obras también integran una reflexión sobre el ser humano y nuestro modo de estar en el mundo.

Por otro lado, esta aproximación invita a considerar el temple anímico de numerosas obras literarias que, como El Zarco, Los de abajo y Pedro Páramo, incorporan sustancialmente las rudas condiciones políticas, económicas y sociales que han aquejado al México moderno y contemporáneo. En vista de la violencia sin precedentes que actualmente alimentan la corrupción, el narcotráfico y el feminicidio, el estudio de obras de tiempos cada vez más remotos a partir de las ideas de un viejo filósofo alemán puede parecer anodino. Sin embargo, no se debe olvidar que los problemas del estado y la sociedad en México no son nuevos y que desde su origen y hasta nuestros días los grandes autores mexicanos han procurado no sólo ponerlos en evidencia, como podría hacerlo el periodismo, sino proponer, a través de la ficción, a partir de ejemplos positivos o negativos, una postura ante ellos. De ese modo, en sus obras literarias se revela una manera de estar en el mundo que suele estar muy atenta tanto a la verdad del mundo como a la condición del ser. El desengaño de corte existencial que agrupa los textos examinados aquí, podrá sin duda identificarse como un tema importante en gran parte de la literatura mexicana y servir de clave interpretativa para aproximarse a las obras de numerosos escritores que, como Altamirano, Azuela y Rulfo, se han ocupado de procesar una realidad continuamente en crisis. 


\section{Bibliografía}

Altamirano, Ignacio M. El Zarco, en Obras completas IV. México: Secretaría de Educación Pública, 1986a. 93-241.

Altamirano, Ignacio M. Atenea, en Obras completas IV. México: Secretaría de Educación Pública, 1986b. 243-287.

Azuela, Mariano. Los de abajo, en Obras completas I. México: Fondo de Cultura Económica, 1958. 320-418.

AzUELA, MARIANO. Algo sobre novela mexicana contemporánea, en Obras completas III. México: Fondo de Cultura Económica, 1960a. 669-711.

Azuela, Mariano. El novelista y su ambiente [I], en Obras completas III. México: Fondo de Cultura Económica, 1960b. 1012-1109.

Blanco Aguinaga, Carlos. "Realidad y estilo de Juan Rulfo", en La ficción de la memoria: Juan Rulfo ante la crítica. Ed. Federico Campbell. México: Universidad Nacional Autónoma de México / Era, 2003. 19-43.

Bradiey, Diarmuid. "The Thematic Import of Azuela's Los de abajo: A Defence", en Forum for Modern Language Studies, 15 (1979): 14-25.

BRUCE-NovoA, JuAN. "La novela de la Revolución mexicana: la topología del final", en Hispania, 74.1 (1991): 36-44.

Díaz Ruanova, Oswaldo. Los existencialistas mexicanos. México: Rafael Giménez Siles, 1982.

Frenk, Mariana. "Pedro Páramo", en La ficción de la memoria: Juan Rulfo ante la crítica. Ed. Federico Campbell. México: Universidad Nacional Autónoma de México / Era, 2003. 44-54.

HARris, Christopher. "En México la literatura viril nunca existió: Mariano Azuela, Los de abajo y el suicidio de Demetrio Macías", en Mariano Azuela y la literatura de la Revolución mexicana. Edición de Rafael Olea Franco. México: El Colegio de México, 2017. 17-36.

Heidegger, Martin. Ser y Tiempo. Trad. Jorge Eduardo Rivera C. Chile: Editorial Universitaria, 1997.

JIMÉNEZ DE BÁeZ, Yvette. "Los de abajo de Mariano Azuela: escritura y punto de partida", en Nueva Revista de Filología Hispánica, 40.2 (1992): 843-874.

KING, MAGDA. A Guide to Heidegger's Being and Time. Albany: State University Of New York Press, 2001.

Merrim, Stephanie. "'Living and Thinking with Those Dislocations': A Case for Latin American Existentialist Fiction", en Hispanic Literatures and the Question of a Liberal Education. Edición de Luis Martín-Estudillo y Nicholas Spadaccini. Hispanic Issues On Line, 8 (2011): 93-109.

Merrim, Stephanie. "The Existential Juan Rulfo: Pedro Páramo, Mexicanness, and the Grupo Hiperión", en MLN 129.4 (2014): 308-329.

MonsiváIS, CARlos. "El Zarco: los falsos y los verdaderos héroes románticos". Prólogo a Ignacio M. Altamirano. El Zarco. México: Océano, 1999. 9-23.

Muñoz, MARIO. "Dualidad y desencuentro en Pedro Páramo", en Cuadernos Hispanoamericanos, 421-423 (1985): 385-398. 
Ortega, Julio. "Enigmas de Pedro Páramo", en La ficción de la memoria: Juan Rulfo ante la crítica. Ed. Federico Campbell. México: Universidad Nacional Autónoma de México / Era, 2003. 337-341.

Perus, Françoise. "Los de debajo de Mariano Azuela y 'El Llano en Ilamas' de Juan Rulfo: Alcances de un vínculo intertextual", en Mariano Azuela y la literatura de la Revolución mexicana. Ed. Rafael Olea Franco. México: El Colegio de México, 2017. 245-273.

Rivas VelázQuez, Alejandro. "Altamirano y su nueva visión de la novela en El ZarCo", en Reflexiones lingüísticas y literarias II. Edición de Rafael Olea Franco y James Valender. México: El Colegio de México, 1992. 169-185.

Rodríguez Monegal, Emir. "Relectura de Pedro Páramo", en La ficción de la memoria: Juan Rulfo ante la crítica. Ed. Federico Campbell. México: Universidad Nacional Autónoma de México / Era, 2003. 121-135.

Roffé, Reina. Juan Rulfo. Autobiografía armada. Buenos Aires: Corregidor, 1973.

RosAles, LuIs. El sentimiento del desengaño en la poesía barroca. Madrid: Cultura Hispánica, 1966.

Rulfo, Juan. Pedro Páramo. México: RM y Fundación Juan Rulfo, 2005.

Rulfo, Juan. "Pedro Páramo, treinta años después", en Cuadernos Hispanoamericanos, 421-423 (1985): 5-8.

Sklodowska, Elzbieta. "“ $¿ A$ que no me lo cree?': Coerciones discursivas en Los de debajo de Mariano Azuela", en Hispamérica, 69 (1994): 23-36.

SOMmers, Joseph. "Los muertos no tienen tiempo ni espacio (un diálogo con Juan Rulfo)", en La ficción de la memoria: Juan Rulfo ante la crítica. Ed. Federico Campbell. México: Universidad Nacional Autónoma de México / Era, 2003. 517-521.

TORO, Alfonso De. Los laberintos del tiempo: Temporalidad y narración como estrategia textual y lectoral en la novela contemporánea (G. García Márquez, M. Vargas Llosa, J. Rulfo, A. Robbe-Grillet). Frankfurt: Vervuert Verlag, 1992.

\section{Pablo García LoAeza}

Enseña en el departamento de Lenguas, literatura y lingüística en la Universidad de West Virginia. Obtuvo su doctorado de la Universidad de Indiana en Bloomington, su maestría en la Universidad de Rhode Island y su licenciatura en la Universidad Iberoamericana. Se ha dedicado a investigar la historiografía hispanoamericana del periodo colonial. Sus artículos han aparecido en revistas como Colonial Latin American Review y Estudios de Cultura Náhuatl, así como en varios volúmenes de ensayos. También ha estudiado la literatura hispanoamericana moderna y ha publicado trabajos al respecto en Altertexto, Chiricú y Revista de Crítica Literaria Latinoamericana. 